\title{
CONTAMINAÇÃO MICROBIOLÓGICA DAS CÉDULAS MONETÁRIAS CIRCULANTES EM FEIRA LIVRE DO INTERIOR DO ESTADO DA BAHIA
}

\author{
MICROBIOLOGICAL CONTAMINATION OF CIRCULATING MONETARY \\ BANKNOTES IN FREE FAIR OF THE INSIDE OF BAHIA STATE
}

\author{
Isabela Queiroz \\ Universidade Federal da Bahia - UFBA
}

\begin{abstract}
Money is perhaps the most exchanged article by people around the world serving as a reservoir of microorganisms that can be transmitted among the population. The aim of the present study was to analyze the contamination of circulating monetary banknotes in a free fair in the interior of Bahia by species of clinical relevance such as Enterobacteria, Staphylococcus spp. and Candida species, in addition to analyzing general contamination. Samples were collected from the surfaces of 50 banknotes in circulation at the fair. The samples were identified and sent to the laboratory, where they were agitated obtaining an initial suspension and from that were made decimals diluted in duplicate in Petri dishes containing blood agar, Agar Sabouraud Dextrose with chloramphenicol, salt Mannitol Agar and MacConkey Agar. Plates were incubated at $37^{\circ} \mathrm{C}$ / $24 h$ (5 days at room temperature for fungi growth). The results obtained in CFU / $\mathrm{mL}$ were analyzed by the ANOVA statistical test (5\%). It was concluded that in the monetary banknotes, samples of all interest microorganisms in the study were collected and that there is a need for the implementation of public policies to minimize the contamination of the bills emphasizing the good habits of personal hygiene among the population.
\end{abstract}

Key words: cross infection, commerce, Staphylococcus, Candida e Enterobactérias.

\section{Resumo}

O dinheiro é talvez o artigo mais trocado por pessoas em todo o mundo servindo como reservatório de microrganismos que podem ser transmitidos entre a população. $O$ objetivo do presente estudo foi analisar a contaminação das cédulas monetárias circulantes em feira livre do interior da Bahia por espécies de relevância clínica como as Enterobactérias, Staphylococcus spp. e espécies de Candida, além de analisar a contaminação geral. Foram coletadas amostras das superfícies de 50 cédulas em circulação na feira livre. As amostras foram identificadas e no laboratório foram agitadas obtendo-se uma suspensão inicial e a partir dessa foram realizadas diluições decimais que foram semeadas em duplicata em placas de Petri contendo os meios de cultura Ágar-sangue, Ágar Sabouraud dextrose com cloranfenicol, Ágar salgado manitol e Agar MacConkey. As placas foram incubadas a 37으 $24 \mathrm{~h}$ (5 dias a temperatura ambiente para crescimento de fungos). Os resultados obtidos em UFC/mL foram analisados pelo teste estatístico ANOVA (5\%). Pôde-se concluir que nas cédulas monetárias foram coletadas amostras de todos os microrganismos de interesse no estudo e que existe necessidade de implementação de políticas públicas para minimização da contaminação das cédulas enfatizando os bons hábitos de higiene pessoal entre a população.

Palavras chave: contaminação cruzada, comércio, Staphylococcus, Candida e Enterobactérias 
Introdução

$\mathrm{Na}$ sociedade moderna houve a popularização do uso de cédulas e das moedas metálicas nas transações comerciais de todos os tipos devido à facilidade de circulação desses objetos monetários $^{1,2}$. O dinheiro, seja na forma de moedas ou cédulas de papel, é talvez o artigo mais amplamente trocado por pessoas todos os dias, em todos os lugares por todo o mundo ${ }^{3,4}$.

O fato de entrarem em contato com muitos indivíduos diariamente tornam as cédulas verdadeiros reservatórios microbiológicos. É relevante considerar a capacidade das mãos como veículo de transmissão de microrganismos patogênicos entre as pessoas assim como as cédulas monetárias que, devido a grande manipulação, também representam fonte de contaminação e de infecção cruzada 5,6,7

$\mathrm{Na}$ literatura mundial existem trabalhos que mostram a contaminação microbiológica do dinheiro de diferentes países evidenciando a capacidade das cédulas monetárias de servirem como fontes de disseminação de microrganismos patogênicos $8,9,10,3,11,4,12,13,14,15,16$. Bhat ${ }^{3}$ observaram que $100 \%$ do universo das notas analisadas estavam com algum tipo de contaminação por microrganismos com característica infecciosa. Kuria ${ }^{15}$ evidenciaram uma grande quantidade de contaminação de relevância epidemiológica nas cédulas monetárias e relataram que as espécies de bactérias Escherichia coli e Salmonella enteritides podem sobreviver nessas cédulas por até 11 e 9 dias, respectivamente, permanecendo viáveis e passíveis de contaminação cruzada. Alwakeel e Nasser ${ }^{10}$ observaram contaminação bacteriana e fúngica em torno de $72 \%$ das cédulas de dinheiro da Arábia Saudita e Igumbor $^{13}$ mostraram contaminação por bactérias e fungos em $96 \%$ das cédulas analisadas na África do Sul.

A análise do dinheiro em circulação pode revelar dados importantes sobre as características sócio-econômicas e higiênicosanitárias de uma determinada área geográfica. Os resíduos de matéria orgânica, as substâncias graxas provenientes das mãos e a porosidade da celulose colaboram para a aderência microbiológica e parasitária nas cédulas monetárias $^{17,18,19,7}$. Segundo Lamichhane ${ }^{16}$, as rotas de transmissão de microrganismos pelo dinheiro é de grande importância para a saúde da população onde a freqüência da infecção é uma indicação geral do nível de higiene local e saneamento básico. Para Gedik ${ }^{4}$ os níveis de higiene de uma comunidade ou sociedade podem contribuir para a grande quantidade de microrganismos encontrados em moedas e cédulas monetárias.

Outro fator relevante na contaminação das cédulas monetárias é a associação positiva com a deterioração do material. Os trabalhos de Lamichhane $^{16}$ e Alwakeel e Nasser ${ }^{10}$ evidenciaram que quanto maior a deterioração da cédula, maior a contaminação por microrganismos patogênicos.

Sabe-se que no Brasil, todas as notas de Real circulantes são contaminadas por bactérias como as espécies de Staphylococcus, provenientes da pele humana e Enterococcus de origem fecal, e ainda podem estar contaminadas com fungos cujos crescimentos são favorecidos pela umidade das mãos ${ }^{5,20,7}$. Esses microrganismos e muitos outros aderem-se a superfície porosa das cédulas de papel favorecendo além de infecções, a agregação de sujidades de todo tipo e, por conseguinte, a deterioração mais rápida da cédula ${ }^{6}$.

A contaminação das cédulas monetárias desperta a necessidade de políticas públicas que incentivem a conscientização da lavagem das mãos por parte da população logo após a manipulação das mesmas evitando dessa maneira a disseminação de doenças higiênicosanitárias que tenham esse meio como fonte de veiculação ${ }^{18,19,7}$. Tal iniciativa não só reduziria o índice de contaminação das cédulas monetárias como também é primordial para que haja diminuição do avanço de epidemias modernas como a atual gripe provocada pelo vírus $\mathrm{H} 1 \mathrm{~N} 1^{17,5,20,7}$

Outro fator agravante é a manipulação de cédulas monetárias por grupos de indivíduos mais susceptíveis ao desenvolvimento de infecções graves como idosos, gestantes, crianças e imunocomprometidos, além dos manipuladores de alimentos cujas mãos freqüentemente são fontes veiculadoras de contaminação para os alimentos de consumo humano ${ }^{18,6,19}$. Nesses casos os cuidados higiênicos de lavagem das mãos após manuseio das cédulas monetárias devem ser redobrados.

Com base no descrito, este estudo teve por objetivo analisar a contaminação das cédulas monetárias circulantes em feira livre do interior da Bahia por espécies de relevância clínica como as Enterobactérias, Staphylococcus spp. e espécies de Candida, além de analisar a contaminação geral das cédulas.

\section{Metodologia}

O estudo foi realizado na feira livre denominada Central de Abastecimento (CEASA) 
de um município de relevância econômica do interior do Estado da Bahia. Para obtenção das amostras, cédulas monetárias utilizadas nas transações comerciais dentro da feira livre pesquisada foram disponibilizadas aleatoriamente totalizando 50 cédulas analisadas. Dessas, 3 eram cédulas de $R \$ 1,00,13$ eram cédulas de $R \$ 2,00,10$ eram cédulas de $R \$ 5,00$, 8 eram cédulas de $\mathrm{R} \$ 10,00,8$ eram cédulas de $R \$ 20,00,2$ eram cédulas de $R \$ 50,00$ e 6 eram cédulas de $\mathrm{R} \$ 100,00$. As amostras foram coletadas utilizando-se swab estéril que foram umedecidos em solução fisiologia ( $\mathrm{NaCl} 0,85 \%)$ e passados em toda a superfície de ambos lados das cédulas, tomando-se o cuidado de manter ambiente asséptico durante a coleta.

Após a coleta, as amostras devidamente identificadas foram introduzidas em tubos contendo $3 \mathrm{~mL}$ meio de cultura TSB (Himedia, Mumbai, Índia) estéril e foram transportadas para o laboratório de Microbiologia onde foram processadas.

No laboratório, os tubos contendo os swabs com as amostras coletadas de cada cédula monetária foram agitados em aparelho agitador de tubos tipo vortex (Phoenix Luterco, Araraquara-SP, Brasil) durante 1 minuto e a partir desta suspensão inicial foram realizadas diluições decimais de $10^{-1}, 10^{-2}$ e $10^{-3}$. A suspensão inicial e as demais diluições de cada amostra coletada foram semeadas em alíquotas de $100 \mu \mathrm{L}$ de forma duplicada em placas de Petri contendo os meios de cultura Ágar-sangue (Himedia, Mumbai, Índia), para contagem total de microrganismos de relevância clínica, Ágar Sabouraud dextrose com cloranfenicol (Himedia, Mumbai, Índia), para isolamento de fungos, Ágar salgado manitol (Himedia, Mumbai, Índia), para crescimento de Staphylococcus spp. e Agar MacConkey (Himedia, Mumbai, Índia), seletivo para Enterobacteriaceae e bacilos entéricos gram-negativos, num total de 400 placas analisadas.

Para a análise, as placas foram incubadas em estufa B.O.D. (demanda bioquímica de oxigênio; Solab. Piracicaba -SP) a $37{ }^{\circ} \mathrm{C}$ durante $24 \mathrm{~h}$ e as placas de ágar Sabouraud dextrose com cloranfenicol permaneceram a temperatura ambiente por mais 5 dias. Passado esse período de incubação, as placas foram analisadas contando-se as colônias formadas em cada uma obtendo o resultado em unidades formadoras de colônias por mililitro (UFC/mL).

Os resultados obtidos em $\mathrm{UFC} / \mathrm{mL}$ foram analisados pelo teste estatístico ANOVA com nível de significância de 5\%.

\section{Resultados e Discussões}

Houve crescimento de UFC em todos os meios estudados, entretanto não foram encontrados parâmetros na literatura que indiquem o nível de contaminação microbiológica que represente risco a saúde humana. Os dados em UFC/mL relativos ao crescimento de colônias de leveduras do grupo Candida, Staphylococcus spp, bactérias entéricas e contagem total de bactérias das amostras coletadas nas cédulas monetárias foram comparados por meio do teste estatístico ANOVA (5\%). Foi possível observar que houve diferença estatisticamente relevante entre as espécies de Candida, Staphylococcus e bactérias entéricas quando comparados com o grupo de contagem total $(p=0,043 ; p=0,009 ; p=0,000$, respectivamente), sendo que 0 número de $\mathrm{UFC} / \mathrm{mL}$ das amostras semeadas em ágar sangue que determinou a contagem total (desvio-padrão $=127,7$ e $p=$ foi maior estatisticamente que nos demais grupos. Também foi possível observar que houve diferença estatística significante entre o número de UFC/mL das espécies de Candida quando comparadas com as espécies de bactérias entéricas $(p=0,019)$, sendo que $o$ maior crescimento foi observado nas espécies de Candida. Quando comparado o crescimento das espécies de Candida com as espécies de Staphylococcus, não foi observada diferença estatística $(p=0,969)$. Foi possível observar que houve diferença estatística relevante entre a contagem das espécies de Staphylococcus com espécies de bactérias entéricas, sendo que houve maior crescimento das espécies de Staphylococcus na cédulas monetárias analisadas.

Figura 1 - Comparação entre o número de UFC/mL entre as espécies de Candida, Staphylococcus,

bactérias entéricas e contagem total de bactérias coletadas das cédulas monetárias

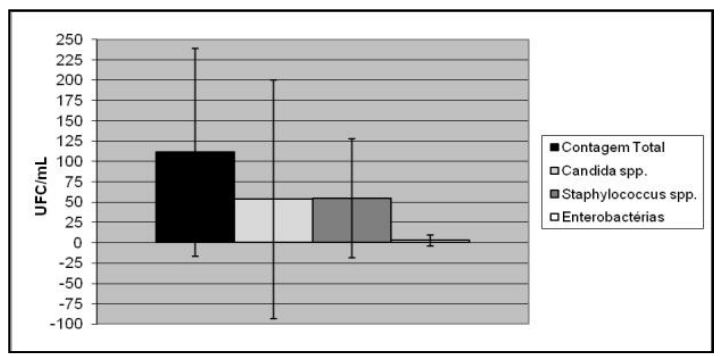

Na literatura internacional são mencionadas várias práticas inadequadas de higiene que contaminam as cédulas monetárias e moedas metálicas. Entre essas práticas os trabalhos evidenciam a má higienização das mãos após uso dos sanitários, umedecimento dos dedos com 
saliva ou água contaminada durante a contagem das cédulas, manipulação de feridas e secreções nasais durante o manuseio do dinheiro, aerossóis gerados por espirros e tosse e contato com cédulas e moedas, transporte das cédulas entre os sutiãs e a pele e transporte das cédulas nas meias $^{9,3,11,14,16}$.

Assim, baseado em tantas evidências de práticas que comprometem a manutenção das condições de higiene das cédulas monetárias e moedas é que estudos em diversos países foram realizados principalmente com o intuito de dimensionar a contaminação parasitária e microbiológica desses objetos de valor monetário e verificar o possível impacto dessa contaminação para a saúde da população $0^{8,9,10,3,11,13,14,16}$.

Mesmo existindo estudos que levantam as questões relacionadas à contaminação do dinheiro, ainda há uma lacuna na literatura acerca desse assunto. A Organização Mundial da Saúde (OMS) recomenda inclusive que mais estudos sejam realizados sobre a transmissão de patógenos através do dinheiro em locais diferentes por todo o mundo, particularmente na Àfrica ${ }^{9}$.

No presente estudo optou-se por coletar amostras de cédulas monetárias que circulam entre as pessoas que trabalham e compram nas feiras livres por ser um local de comércio de produtos alimentícios (frutas, hortaliças, legumes entre outros) e pela relação desses produtos com várias doenças veiculadas por alimentos contaminados $^{19}$. Lamichhane ${ }^{16}$ relataram que as falhas da higienização adequada das mãos de manipuladores de alimentos que tem envolvimento com o dinheiro no comércio de produtos alimentícios podem colocar o serviço em risco. No estudo de Ahmed $^{8}$ os autores concluíram que muitos cuidados devem ser tomados durante o manuseio do dinheiro e na preparação e manipulação dos alimentos para evitar problemas de contaminação cruzada. Kuria ${ }^{15}$ destacaram ainda o potencial das cédulas monetárias para espalhar microrganismos patogênicos reforçando a necessidade de higienização adequada das mãos após manuseio de dinheiro especialmente quando lidam simultaneamente com alimentos.

A escolha pela coleta na feira livre também visou salientar a importância da higienização adequada dos produtos comercializados nesses ambientes antes de serem processados ou armazenados nas residências e estabelecimentos alimentícios, já que as cédulas monetárias contaminadas podem contaminar por sua vez esses produtos através das mãos das pessoas ${ }^{6}$.
Poucos estudos foram realizados no Brasil acerca do assunto, mas observou-se que, assim como a presente pesquisa, Heinen ${ }^{20}$, Souza ${ }^{19}$ e Sudré$^{7}$ também priorizaram a análise da contaminação microbiológica e parasitária de cédulas monetárias circulantes em estabelecimentos que comercializam produtos alimentícios.

No presente estudo foi possível observar que foram coletadas poucas Enterobactérias, espécies da microbiota intestinal humana que é parâmetro para indicação de contaminação fecal, com relação às demais espécies. Sugere-se que a pouca quantidade dessas espécies coletadas no presente estudo tenha relação com a baixa capacidade de aderência da espécie ao material das cédulas monetárias. O que parece ser certo é que não existem todas as condições físicas e químicas de crescimento que essas espécies precisam para colonizar as cédulas monetárias. Acredita-se que essas espécies existam nas mãos das pessoas e nas cédulas monetárias sem condições favoráveis para se estabelecer como colônia nesse local, o que não descarta a possibilidade de que as cédulas monetárias sejam transmissoras dessas espécies relacionadas com diferentes moléstias em seres humanos $^{6}$. O estudo de Igumbor $^{13}$, que objetivou identificar microrganismos patogênicos das notas em circulação na África (região da província de Limpopo), também isolou Enterobactérias como Escherichia coli $(9,2 \%)$ e Klebsiella spp. (11\%) em menor número que as demais espécies isoladas corroborando com o presente estudo, assim como o trabalho de Kuria ${ }^{15}$ onde as Enterobactérias foram isoladas das notas de dinheiro do Quênia em índices menores (15\%) que o restante dos isolados. Já no estudo de Bhat $^{3}$ a espécie Escherichia coli, uma Enterobactéria, foi a espécie de bactéria mais isolada (64\%) das cédulas monetárias da cidade de Niterói no Brasil. As diferenças encontradas entre o presente estudo e o estudo de Bhat ${ }^{3}$ podem estar relacionadas com os métodos de coleta e meios de cultura utilizados para isolamento das espécies.

Uma evidência muito importante do presente estudo é que houve um nível significativo de contaminação geral por espécies bacterianas constatada pelo crescimento das colônias em meio de cultura ágar sangue, o que denota a capacidade das cédulas monetárias de serem reservatórios microbiológicos consideráveis com capacidade de serem veiculadoras de microrganismos patogêncicos e contaminantes das mãos e de quaisquer produtos onde entrarem em contato direto ou 
indiretamente. Sem dúvida, esperava-se como resultado o maior número de UFC nesse grupo, uma vez que o meio de cultura ágar sangue é um meio enriquecido que propicia o desenvolvimento de muitas espécies bacterianas ${ }^{19}$.

Apesar de não ter sido observada diferença estatística no número de UFC das leveduras do gênero Candida com as espécies de Staphylococcus, essas espécies mostraram-se contaminantes das cédulas monetárias em número considerável e significativo, o que é preocupante, já que as leveduras do gênero Candida são fungos que causam infecções oportunistas aproveitando-se das condições de baixa imunidade do hospedeiro para se estabelecerem como patógenos e as espécies de Staphylococcus são bactérias causadoras de graves infecçõs principalmente em ambientes hospitalares e estão relacionadas com graves moléstias gastro-intestinais provocadas por contaminação de produtos alimentícios ${ }^{18}$. A presença de Staphylococcus spp. pode ser justificada devido ao fato de pertencerem a microbiota da pele, inclusive das mãos ${ }^{19}$.

Outro estudo com cédulas monetárias realizado em outras regiões do Brasil revelam que $100 \%$ das mesmas contêm algum grau de contaminação microbiana, sendo que segundo o estudo de Souza (2006) $75,5 \%$ delas apresentaram bactérias do gênero Gram-positivo, $69,5 \%$ Gram-negativos enquanto que $26,5 \%$ das cédulas analisadas estavam contaminadas por espécies fúngicas. Em outras partes do mundo foram também observadas maiores contaminações de cédulas monetárias por bactérias Gram-positivas, sendo a espécie Staphylococcus a mais prevalente dentre os isolados ${ }^{10,4,13,14}$.

Com relação à presença de espécies fúngicas, existem poucos estudos que se preocuparam em analisar a contaminação das cédulas monetárias pelas espécies de fungos patogênicos para seres humanos. Dentre esses, os trabalhos de Alwakeel \& Nasser ${ }^{10}$ e Igumbor $^{13}$ mostraram, assim como no presente estudo, a prevalência das leveduras do gênero Candida nos isolados de cédulas monetárias. Alwakeel \& Nasser ${ }^{10}$ também isolaram outras espécies fúngicas das cédulas monetárias como Penicillium spp, Aspergillus spp. e Rhizopus spp. Nos estudos de Kalita ${ }^{14}$ e Kuria ${ }^{15}$ houve o isolamento de espécies de leveduras e bolores que podem causar infecções oportunistas. 0 único estudo que relatou maior isolamento de fungos da espécie Aspergillus foi o de Akoachere ${ }^{9}$, embora tenham identificado outras espécies de fungos entre os isolados de cédulas monetárias.

Diante dessa evidencia, alguns países, ressaltando-se os desenvolvidos, adotaram medidas para a manutenção das condições higiênicas das cédulas e moedas. No Japão realiza-se a esterilização por calor das cédulas monetárias e a substituição das cédulas de celulose pelas de polímero ${ }^{14}$. Nos Estados Unidos instituiu-se um departamento responsável pelas cédulas e moedas deterioradas e na Austrália aderiu-se às notas de plástico que podem ser lavadas ${ }^{16}$. Outra medida interessante foi adotada na China onde as cédulas e moedas permanecem em "quarentena" durante 24 horas antes de ser recirculada entre a população ${ }^{3}$.

Vale salientar que na pesquisa de $\mathrm{Gedik}^{4}$ onde foram analisados o crescimento $e$ transmissão de espécies multi-droga-resistentes no Dólar (Estados Unidos), Euro (países europeus), Kuna (Croácia), Leu (Romenia), Dirhan (Marrocos), Dolar canadense (Canadá) e Rupe (Índia) foi evidenciado que somente o dinheiro croata não permitiu o crescimento de nenhuma das espécies testadas. Os autores não conseguiram informações sobre o material constituinte da Kuna, o que poderia ser interessante para outros países.

No estudo de Enemour ${ }^{11}$ relata-se que medidas como a utilização de cartões de crédito e cheque podem refletir na diminuição da contaminação microbiológica veiculada por cédulas monetárias e moedas entre as transações comerciais. Os autores também citam que uma desinfecção regular da moeda e cédulas depositadas em bancos com luz ultravioleta ou vapores de formalina são sugestões interessantes para o controle da contaminação do dinheiro, além da retirada regular de notas deterioradas de circulação pelas autoridades federais.

Existe um consenso na literatura sobre a evidência de que a correta higienização das mãos antes e após a manipulação do dinheiro e a boa higiene pessoal sejam as medidas mais relevantes para a diminuição e controle das condições higiênicas das cédulas e moedas monetárias em todos os países ${ }^{17,8,9,10,3,11,4,12,13,14,15,16,18,19,7}$.

Com os resultados desse estudo, de uma forma indireta, é possível ressaltar a importância dos cuidados de higiene principalmente após a manipulação das cédulas monetárias, antes do manuseio de produtos alimentícios, antes dos cuidados às pessoas com baixa imunidade e pessoas hospitalizadas e como limitador de doenças epidêmicas veiculadas pelas mãos ${ }^{18}$. 
Embora os resultados desse estudo não possibilitem apontar o grau de periculosidade das cédulas monetárias como disseminadoras de microrganismos patogênicos para os seres humanos, através dos dados confirmou-se que as cédulas monetárias são reservatórios de microrganismos de grupos com potencial de causar doenças na população.

Esse estudo aponta para a necessidade de que sejam feitas outras pesquisas que analisem as condições microbiológicas das cédulas monetárias e de outros objetos de transações comerciais como moedas e cartões de créditos $^{19}$. Além disso, o estudo reafirma a necessidade da implementação de políticas públicas para a conscientização sobre o potencial de contaminação das cédulas monetárias e da lavagem das mãos, com o intuito de minimização das infecções em âmbito hospitalar, das epidemias e das doenças gastro-intestinais na população.

\section{Conclusões}

Com base nos resultados do estudo foi possível concluir que:

a) Nas cédulas monetárias foram coletadas amostras de todos os microrganismos de interesse nesse estudo, ou seja, leveduras do gênero Candida, Staphylococcus e Enterobactérias;

b) As cédulas monetárias mostraram-se com contaminação microbiológica geral significativa, constatado através da contagem total de microrganismos;

c) A contaminação das cédulas monetárias por Enterobacteriacea foi menor em relação aos demais grupos de interesse nesse estudo, ou seja, do que as leveduras do gênero Candida e as espécies de Staphylococcus;

d) As cédulas monetárias apresentaram contaminação por leveduras do gênero Candida e por espécies de Staphylococcus de forma semelhante;

e) As cédulas monetárias circulantes em feira livre podem servir como fontes de disseminação de microrganismos relacionados com doenças de relevância clínica;

f) Existe necessidade de implementação de políticas públicas para minimização da contaminação das cédulas enfatizando os bons hábitos de higiene pessoal entre a população.

\section{Referências}

1. TAVARES, M. C.; FIORI, J. L. Poder e dinheiro: uma economia política da globalização. Petrópolis: Editora Vozes, 1998.

2. VINCENTINO, C.; DORIGO, G. História para o ensino médio História Geral e do Brasil. São Paulo: Editora Scipione, 2003.

3. BHAT, N. et al. An Assessment of Oral Health Risk Associated with Handling of Currency NotesInt J Dent Clin, v. 2, n. 3, p. 14-6, 2010.

4. GEDIK, H. et al. Money and transmission of bacteria. Antimicrob Resist Infect Control, p. 222, 2013.

5. CHEHTER, L. et al. Parasitoses intestinais. Rev Bras Med, v. 51, p. 125-32, 1994.

6. MURRAY, P. R. et al.Microbiologia Médica. Rio de Janeiro: Editora Guanabara Koogan, 1998.

7. SUDRÉ, A. P. et al.Estudo da contaminação de moedas e cédulas de dinheiro circulantes na cidade de Niterói- RJ. Rev Patol Trop, v. 41, n. 4, p. 465-70, 2012.

8. AHMED, S.U. et al. Evaluation of the Microbial Contamination of Bangladesh Paper Currency Notes (Taka) in Circulation. Adv Biol Res, v. 4, n. 5, p. 266-71, 2010.

9. AKOACHERE, J. F. T. K. et al. Public health implications of contamination of Franc CFA (XAF) circulating in Buea (Cameroon) with drug resistant pathogens. BMC Res Notes, v. 7, n. 16, p. 1013, 2014.

10. ALWAKEEL, S. S.; NASSER, L. A. Bacterial and Fungal Contamination of Saudi Arabian Paper Currency an Cell Phones. Asian J Biol Sci, v. 4, n. 7, p. 556-62, 2011.

11. ENEMUOR, S.C., et al. Microbial contamination of currency counting machines and counting room environment in selected commercial Banks. Sci Res Essays, v. 7, n. 14, p. 1508-11, 2012.

12. HOSEN, M. J. et al. Contamination of Coliforms in Different Paper Currency Notes of Bangladesh. Pak J Biol Sci, v. 9, n. 5, p. 868-70, 2006.

13. IGUMBOR, E. O. et al. Microbiological analysis of banknotes circulating in the Venda region of Limpopo province, South Africa.S Afr J Sci, v. 103, p. 365-66, 2007.

14. KALITA, M. et al. Isolation of Cultivable Microorganisms from Polish Notes and Coins. Pol J Microbiol, v. 62, n. 3, p. 281-86, 2013.

15. KURIA, J. K. N. et al. Profile of Bacteria and Fungi and Money Coins. East Afr Med J, v. 86, n. 4, p. 151-55, 2009. 
16. LAMICHHANE, J. et al. Risk of Handling Paper Currency in Circulation Chances of Potential Bacterial Transmittance. Nepal J Sci Technol, v. 10, p. 161-66, 2009.

17. AYRES, A. F. S. M. C. et al. Contaminação microbiana de cédulas de real. J Bras Med, v. 81, n.3, p. 40-50, 2001.

18. MONTEIRO, C. L. B. et al. Caracterização de Estafilococos encontrados em dinheiro brasileiro coletado em ambiente hospitalar. J Bras Med, v. 81, n.4, p.17-24, 2001.

19. SOUZA, A. C. S. et al. Microrganismos Encontrados em Dinheiro Brasileiro Coletado em Feira Livre. NewsLab, v. 77, 2006.

20. HEINEN, R. C. et al. Análise microbiológica de cédulas circulantes em feira livre do município de Belford Roxo, RJ- Nota de Pesquisa. Rev Saúde Fís Ment, v. 1, n. 1, 2012.

\section{Endereço para Correspondência}

Universidade Federal da Bahia - UFBA

Rua Augusto Viana, s/n - Palácio da Reitoria,

Canela, Salvador BA

CEP: 40110-909

e-mail: bella_s_2@hotmail.com

Recebido em 10/10/2018

Aprovado em 12/03/2019

Publicado em 18/03/2019 